\title{
Bilateral carotid neo-bifurcation by symptomatic elongation of the common and internal carotid artery
}

\author{
Ana ve internal karotis arterin semptomatik elongasyonu ile iki taraflı karotis neobifurkasyonu \\ Valentin Govedarski' ${ }^{(0)}$, Elitsa Dimitrova' ${ }^{1}$, Zornitsa Vassileva ${ }^{2}$ \\ 'Department of Vascular Surgery, University Hospital Saint Ekaterina, Sofia, Bulgaristan \\ 2Department of Pediatric Cardiology, National Cardiology Hospital, Sofia, Bulgaria
}

\begin{abstract}
A 53-year-old female patient was admitted to our clinic with neurological and ophthalmological symptoms and resistant arterial hypertension. After two-stage operation including bilateral carotid resection and carotid neo-bifurcation creation, the blood flow through the vascular regions with abnormal hemodynamics returned to normal and the symptoms of the patient resolved completely.
\end{abstract}

Keywords: Carotid artery, dolichoarteriopathy, elongation, coiling, kinking, neo-bifurcation.

The elongation of the carotid arteries is a dolichoarteriopathy which may present as tortuosity, kinking, or coiling of the extracranial carotid arteries. This type of anomaly occurs in 10 to $25 \%$ of the general population. ${ }^{[1]}$ The possible causes include developmental abnormalities, fibromuscular dysplasia, age-related degeneration, atherosclerosis, hypertension, post-carotid endarterectomy changes, and normal anatomical variations. ${ }^{[2]}$

Dolichoarteriopathy of the internal carotid artery (DICA) may remain asymptomatic or may present with hemispheric and non-hemispheric symptoms. Kinking and coiling are suggestive of neurological symptoms in two main ways: $(i)$ thromboembolic mechanism which is due to endothelial lesions as a result of turbulence at the site of arterial bending, and (ii) hemodynamic mechanism which seems to play an important role both at rest and in motion. ${ }^{[3]}$ Some authors have reported

\section{$\ddot{O} Z$}

Elli üç yaşında kadın hasta, nörolojik ve oftalmolojik semptomlar ve dirençli arteriyel hipertansiyon ile kliniğimize başvurdu. İki taraflı karotis rezeksiyonu ve karotis neobifurkasyon oluşturulmasından oluşan iki aşamalı ameliyat sonrasında, hemodinamik anormalliği olan vasküler bölgelerdeki kan akışı normale döndü ve hastanın semptomları tamamen düzeldi.

Anahtar sözcükler: Karotis arter, dolikoarteriyopati, elongasyon, kıvrılma, bükülme, neobifurkasyon.

that the smaller (more acute) the angle of the arterial bending, the greater the degree of the hemodynamic disturbances.

No guidelines for the management of DICA have been established yet and the principles of decision making are primarily based on the results of clinical trials showing that surgical correction of symptomatic isolated carotid elongation with coil or kink leads to symptomatic improvement and prevention of stroke. The majority of patients with non-hemispheric complaints report total symptom relief after carotid surgery.

In general, surgical treatment is recommended for patients with transient ischemic attacks (hemispheric symptoms), asymptomatic patients presenting with kinking with an angle less than $30^{\circ}$ and those with contralateral carotid artery occlusion, and patients with non-hemispheric symptoms (after other neurological or

Received: September 24, 2019 Accepted: January 06, 2020 Published online: April 22, 2020

Correspondence: Zornitsa Vassileva, MD. Department of Pediatric Cardiology, National Cardiology Hospital, 1431 Sofia, Bulgaria. Tel: 359898319361 e-mail: drvass@abv.bg 

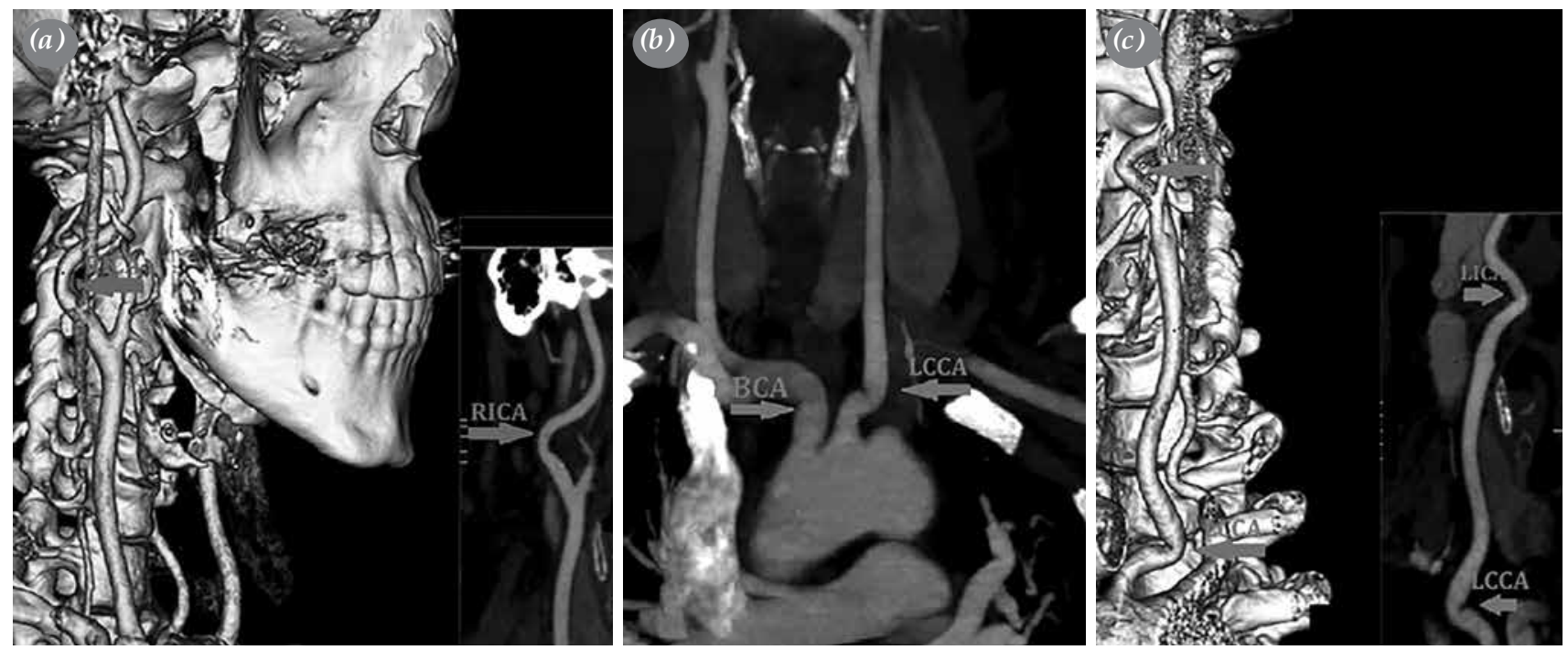

Figure 1. Preoperative computed tomography-carotidography. (a) S-shaped RICA which was elongated and non-stenotic. (b) Kinking of BCA with an angulation of $90^{\circ}$ and kinking of LCCA with $60^{\circ}$ angulation which was located 2-cm away from the ostium and was non-stenotic. (c) Elongation and kinking of LCCA and of LICA.

RICA: Right internal carotid artery; LCCA: Left common carotid artery; LICA: Left internal carotid artery; BCA: Brachiocephalic artery.

non-neurological causes are ruled out) with confirmed elongation and kinking of the carotid arteries on computed tomography (CT)-carotidography. ${ }^{[4]}$ The correction of the elongation of the carotid arteries includes vascular reconstructions with resection and/or carotid neo-bifurcation creation with or without patch plasty and bypass grafting.

In this article, we present a case of successful surgical treatment of bilateral elongation and kinking of the common carotid artery (CCA) and internal carotid artery (ICA).

\section{CASE REPORT}

A 53-year-old female patient presented to our clinic with symptoms of vertigo, severe headache, paresthesia which initially affected the left side of the head, but gradually progressed to the entire left side of the body, and visual disturbances - approximately twice weekly episodes of bilateral scintillations which were more pronounced for the left eye. These complaints started two years ago and worsened to unbearable within the last weeks. The symptoms were accompanied by quadruple combination therapy (angiotensin-converting enzyme inhibitor, calcium channel blocker, beta-blocker, and nitrate)-resistant arterial hypertension with frequent hypertensive crises. The patient was consulted with different specialists and was treated symptomatically without any relief. The routine preoperative cardiological examination, chest $\mathrm{X}$-ray, and laboratory test findings were normal, and the consultations with the neurologist and ophthalmologist indicated no abnormalities which could explain the described complaints. On cranial CT scan, no parenchymal changes were detected. To clarify the etiology of the symptoms, Duplex ultrasound (DUS) scanning of the carotid arteries was performed which revealed bilateral elongation of the ICA without stenosis. The maximal blood flow velocity in the right ICA was $135 \mathrm{~cm} / \mathrm{s}$ and $165 \mathrm{~cm} / \mathrm{s}$ in the left ICA. Computed tomography-carotidography (Figure 1) showed a S-shaped right ICA which was elongated and non-stenotic (Figure 1a) and kinking of truncus brachiocephalicus with an angulation of $90^{\circ}$, free of stenosis (Figure 1b). On the left side, there were tandem elongations of the CCA with kinking with $60^{\circ}$ angulation which was located $2-\mathrm{cm}$ away from the ostium and was non-stenotic (Figure 1b, c) with maximal blood flow velocity of $98 \mathrm{~cm} / \mathrm{s}$ and of the left ICA. The remaining segments, the vertebral and the subclavian arteries, were not affected. There were no abnormalities of the intracranial vessels. As the patient had severe symptoms which were caused by the elongation and kinking of the carotid arteries, she was indicated for surgery; the anatomy of the lesions precluded endovascular treatment. A written informed consent was obtained from the patient.

After heparinization with 5,000 UI unfractionated heparin and by medically controlled hypertension, the left CCA and its bifurcation were exposed through an incision along the anterior border of 


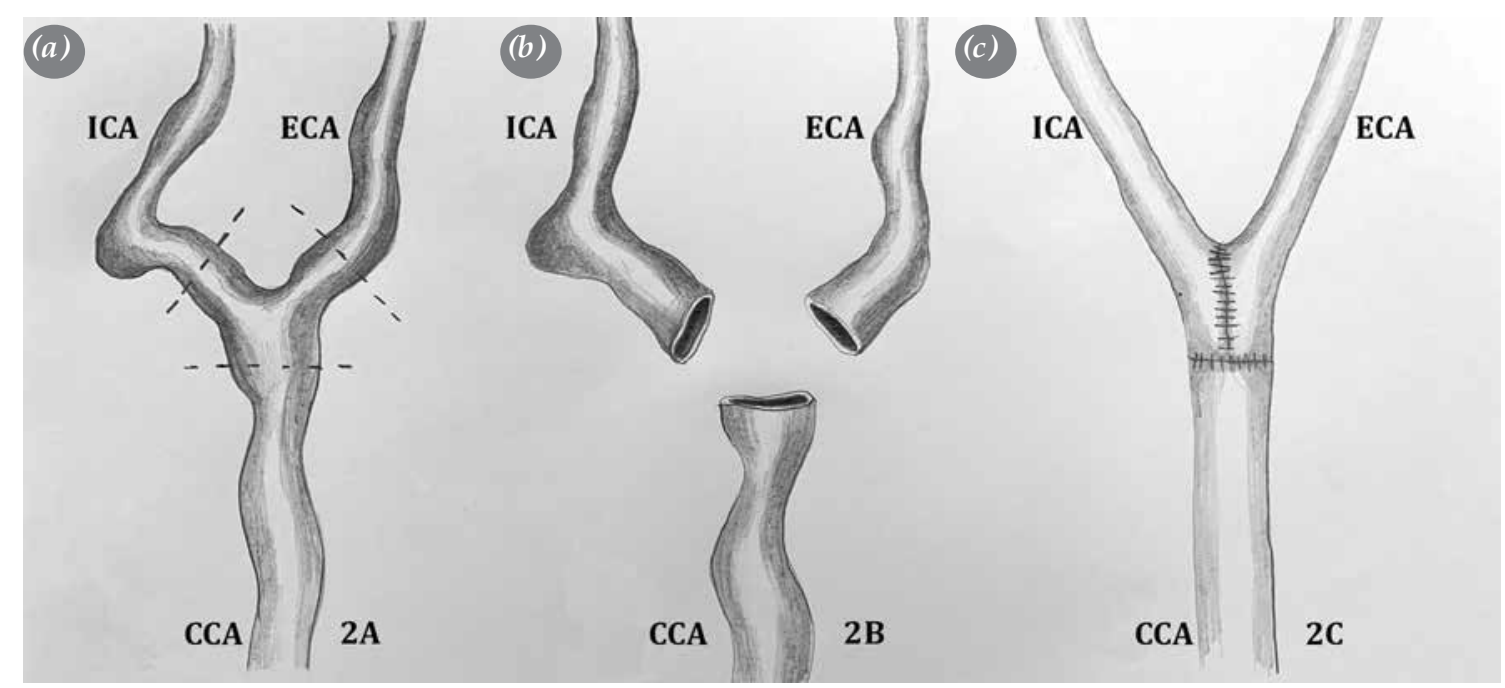

Figure 2. Operation scheme. (a) Preoperative elongation and kinking of CCA and ICA; resection lines are marked. (b) ICA, ECA, and CCA were resected, the abundant regions were removed (not shown). (c) Neo-bifurcation was formed as the ICA and ECA were first connected side-to-side and this anastomosis was, then, attached end-to-end to the resected part of the CCA.

CCA: Common carotid artery; ICA: Internal carotid artery; ECA: External carotid artery.

the sternocleidomastoid muscle. The left ICA was followed maximally in the cranial direction and the left CCA was exposed as near as possible to its origin from the aorta. After clamping of the CCA, external carotid artery (ECA) and ICA, total resection of the bifurcation of the left CCA was performed. Traction was applied on the distal ends of the ICA and ECA, and the redundant regions were resected; about $1 \mathrm{~cm}$ of the length of CCA and $2 \mathrm{~cm}$ from the ICA were removed. Neo-bifurcation was formed, as the ICA and ECA were first connected side-to-side and this anastomosis was, then, attached end-to-end to the resected part of the CCA (Figure 2). A 7/0 prolene suture was used.

Postoperative CT-carotidography showed a normal anatomy of the left ICA without kinking (Figure 3b). On DUS examination, no pathological blood flow was detected. The patient did not have any neurological deficit in the early postoperative period or at two months of follow-up after the intervention. The severity of vertigo, headache, and scintillations was reduced by nearly half. At the second postoperative visit three months after the procedure, ophthalmological symptoms still persisted, but to a lesser degree than before the operation and vertigo and left-sided paresthesia were less pronounced, but not completely resolved. The histological examination of the left ICA showed edema of the endothelial cells, expansion and stratification of the subendothelial layer, and thinning and fragmentation with areas of full loss of elastic lamella. Stratification of the elastic and smooth muscle structures by small clefts was observed with moderate vascularization of the adventitia.

As the symptoms were not fully eliminated and for the persistent kinking on the right ICA, a decision for a second operation was made. Contralateral carotid reconstruction was performed four months after the
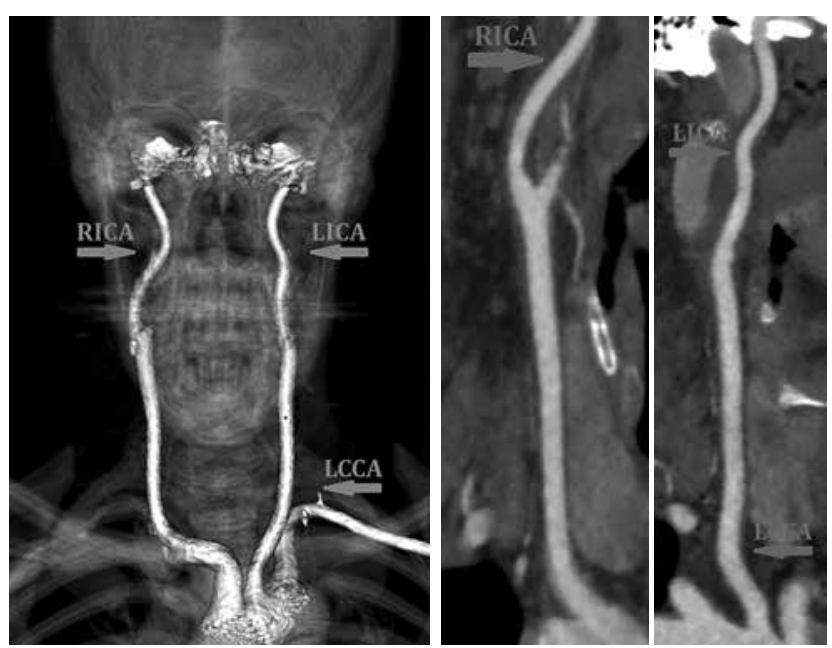

Figure 3. Postoperative computed tomography-carotidography demonstrating restoration of normal anatomy and patent vascular reconstructions bilaterally.

RICA: Right internal carotid artery; LCCA: Left common carotid artery; LICA: Left internal carotid artery. 
first operation using the same technique: resection of the elongated regions and neo-bifurcation creation by anastomosing of the right ECA, right ICA, and right CCA. No neurological deficit was observed neither in the early postoperative period nor at one month of follow-up after the operation. Neurological and the ophthalmological symptoms resolved completely. Postoperative CT-carotidography demonstrated restoration of the normal anatomy of the two carotid trunks and neo-bifurcations bilaterally (Figure 3). On DUS, no residual kinking nor increased blood flow velocity was demonstrated. Vertigo improved significantly and the visual disturbances were regressed. During both operations, transcranial DUS was used for monitoring. Test clamping showed lack of reduction of the cerebral blood flow by medically controlled hypertension and this was the reason for not using shunting during the procedure. The patient was scheduled for a visit one year after the second operation and she had no neurological or ophthalmological symptoms. Cranial CT revealed no parenchymal changes, and CT angiography demonstrated normal anatomy of both ICAs and neo-bifurcations.

\section{DISCUSSION}

A significant clinical improvement in the presented case confirms the appropriate choice of surgical treatment and our hypothesis suggesting that the altered cerebral hemodynamics due to elongation and kinking of the carotid arteries are the major causes of the symptoms.

The presence of bilateral elongation of both ICA and CCA required not only ICA reimplantation, but also CCA straightening. Bilateral neo-bifurcation was performed, including bilateral carotid body resection due to the anatomical position of the anomaly. Usually, bilateral resection of the carotid body is indicated in cases with bilateral tumors located in this region, but is also being studied in difficult-to-control arterial hypertension cases. In our case, stenting was not feasible due to the lack of stenosis and the elongation of the carotid arteries.

More interestingly, the severity of symptoms of our patient was reduced by almost $50 \%$ after the first operation, and we observed complete resolution of the pathological manifestations after the second operation. The kinking of the brachiocephalic artery was not treated, as this alteration was not considered significant and due to favorable therapeutic outcomes after two procedures.

The main goals of the treatment of carotid artery stenosis and/or elongation are to achieve symptom control and to prevent progression of cerebrovascular insufficiency and ischemic stroke. Ballotta et al. ${ }^{[4]}$ conducted a prospective, randomized-controlled trial comparing surgical and medical treatment for isolated ICA elongation with coiling or kinking in 182 symptomatic patients. The authors concluded that surgical correction of symptomatic ICA coiling or kinking prevented stroke better than medical treatment and patients with non-hemispheric complaints reported total symptom relief after carotid surgery. In another study, Gavrilenko et al. ${ }^{[5]}$ compared surgical and conservative treatments by pathological kinking of ICA and found that operative management was an effective method for preventing progression of cerebrovascular insufficiency. The authors also proposed therapeutic indications for DICA in detail as follows: (i) ICA stenosis $\geq 60 \%$ with atherosclerotic plaques and any degree of cerebrovascular insufficiency; and (ii) ICA stenosis $<60 \%$ with atherosclerotic plaques, moderateto-severe cerebrovascular insufficiency in combination with either S- or C-shaped DICA, a linear blood flow rate of $\geq 110 \mathrm{~cm} / \mathrm{s}$ and turbulent blood flow. Based on the limited number of randomized-controlled clinical trials, the 2017 Clinical Practice Guidelines of the European Society for Vascular Surgery state the followings: 1) Surgical intervention for asymptomatic isolated coils/kinks of the ICA is not recommended (Class IIIC recommendation); and 2) Symptomatic patients with isolated coils/kinks may be considered for surgical correction, but only following multidisciplinary team review and provided no other cause for transient ischemic attack or stroke symptoms can be identified - (Class IIB recommendation) ${ }^{[6]}$ In our case, we made a decision for an intervention based on the severity of the complaints, the inability to find another cause of the symptoms, and the lack of efficacy of the medical treatment.

In conclusion, despite the benefits of surgical treatment of dolichoarteriopathy of the internal carotid artery in the aforementioned studies, the treatment strategy still remains a controversial topic which has to be studied further. As dolichoarteriopathy of the internal carotid artery has a high incidence, there is a need for the development of guidelines for the management of these conditions with the most appropriate therapeutic approaches.

\section{Declaration of conflicting interests}

The authors declared no conflicts of interest with respect to the authorship and/or publication of this article.

\section{Funding}

The authors received no financial support for the research and/or authorship of this article. 


\section{REFERENCES}

1. Cvetko E. Concurrence of bilateral kinking of the extracranial part of the internal carotid artery with coiling and tortuosity of the external carotid artery--a case report. Rom J Morphol Embryol 2014;55:433-5.

2. Aleksic M, Schütz G, Gerth S, Mulch J. Surgical approach to kinking and coiling of the internal carotid artery. J Cardiovasc Surg (Torino) 2004;45:43-8.

3. Lee SW, Antiga L, Spence JD, Steinman DA. Geometry of the carotid bifurcation predicts its exposure to disturbed flow. Stroke 2008;39:2341-7.

4. Ballotta E, Thiene G, Baracchini C, Ermani M, Militello C, Da Giau G, et al. Surgical vs medical treatment for isolated internal carotid artery elongation with coiling or kinking in symptomatic patients: a prospective randomized clinical study. J Vasc Surg 2005;42:838-46.

5. Gavrilenko AV, Abramian AV, Kuklin AV. Comparative analysis of the outcomes of surgical and conservative treatment of patients with pathological kinking of carotid arteries. Angiol Sosud Khir 2012;18:93-9.

6. Naylor AR, Ricco JB, de Borst GJ, Debus S, de Haro J, Halliday A, et al. Editor's Choice - Management of Atherosclerotic Carotid and Vertebral Artery Disease: 2017 Clinical Practice Guidelines of the European Society for Vascular Surgery (ESVS). Eur J Vasc Endovasc Surg 2018;55:3-81. 